\title{
Which Technologies Do Pre-Service Teachers Prefer to Use While Presenting Their Teaching Skills and for What Purposes Do They Use These Technologies?
}

\author{
Fatma Sasmaz Oren ${ }^{1}$ \\ ${ }^{1}$ Faculty of Education, Manisa Celal Bayar University, Manisa, Turkey \\ Correspondence: Fatma Sasmaz Oren, Faculty of Education, Manisa Celal Bayar University, Manisa, Turkey. \\ E-mail: fsasmaz@gmail.com
}

Received: July 5, 2017

Accepted: July 10, 2017

Online Published: August 9, 2017

doi:10.5539/hes.v7n3p103

URL: http://doi.org/10.5539/hes.v7n3p103

\begin{abstract}
This research aims to determine the technologies that pre-service science teachers prefer to use in micro teaching presentations performed for improving their teaching skills and to determine the purposes of using these technologies. For this purpose, the case study model was used in the research. The research was made with some 48 pre-service science teachers. In the research, data was collected from the presentation files the pre-service science teachers had prepared with respect to the microteaching applications, from the instructor's observation notes on their presentations, from the view form and from the semi-structured interviews. According to the findings obtained from the research, the pre-service science teachers used computers, projection apparatuses, overhead projectors, videos, animations, simulations and microscopes the most in the microteaching applications The pre-service science teacher's expressed that they used technology primarily for reasons such as enhancing the comprehensibility of the subject, concretizing abstract subjects, ensuring visuality and saving time. Considering these results, some recommendations were made regarding the use of technology in science courses.
\end{abstract}

Keywords: pre-service teachers, teaching skill, technology education, use of technology

\section{Introduction}

The literature contains many studies that emphasize the importance of the integration of technology into education and into the learning process (Duran, Brunvand, \& Fossum, 2009; Chay, Wong, \& Gao, 2009; Tor \& Erden, 2004; Keeler, 2008; Smolin \& Lawless, 2011). According to Bell (2011), learners, teachers and managers are trying to integrate technology into learning in formal and informal settings. Technology-enhanced, student-centered learning environments provide interactive, complimentary activities that enable individuals to address unique learning interests and needs, and deepen understanding (Hannafin \& Land, 1997). According to Kabakç1-Yurdakul (2011), helping pre-service teachers gain technological and pedagogical content knowledge in the process of pre-service education is quite important for effective technology integration. However, Niess (2005, p. 509) expresses her opinion about the integration of education and technology as follows: "Education must shift to incorporate computer-based, electronic technologies integrating learning with these technologies within the context of the academic subject areas". Teachers need to be technically competent with using computers and integrate technology into teaching and learning activities (Koh, 2011). According to Stobaugh and Tassell (2011), technology is integral to education and technology integration is a critical element for pre-service teacher education. When these views are taken into consideration, it is understood that the integration of technology into the education of teachers is also as quite important as its integration into all levels of education and instruction.

One of the significant subjects for discussion in the education of teachers is the matter of teachers' ability to successfully integrate the technology in their classes (Lee, Y. \& Lee, J., 2014). Pre-service teachers need to have the ability to exhibit the skills for using the technology at a very good level and for using such technologies at an optimal level of efficiency in the teaching-learning process (Gunduz \& Odabasi, 2004). In this case, it can be said that teacher training needs to provide good guidance for the pre-service teachers in acquiring the field skills as well as in the matter of technology use. Without proper teacher professional development and shift of focus in curricula, technology use will be limited to delivery of knowledge and digitisation of content (Akcaoglu, Gumus, 
Bellibas, \& Boyer, 2015). Niess (2008) expresses his thoughts on this matter as follows: "teacher preparation programs must guide pre-service teachers to develop strategies and a presence of mind that transcends modern classrooms". The teacher must not only know a content-specific technological tool but also understand how that tool could be properly used in lessons, how to operate the tool and how to modify the tool to fit the intended purpose (Young, J. R., Young, J. L., \& Hamilton, 2013). When this view is taken into consideration, in order for a teacher to exhibit the subject matter skills, the importance of training the pre-service teachers with necessary guidance in the field of the use of technology and of determining the situation regarding the use of technology becomes obvious.

Various technologies are being used in each area and in different stages of the teacher preparation nowadays. One of such fields is the science education field. According to Campbell and Abd-Hamid (2013), science content, pedagogy, and technology are conceptualized as a tripartite of important influences that can converge in meaningful ways to influence science learning experiences. Technology-enhanced collaboration technologies in science education can help participants perform critique beyond physical boundaries and time constraints and it also provides many opportunities for scaffolding strategies that can be used to help students develop their critical knowledge (Shen, 2010). Technology-based innovations in science education and especially for the training of teachers will just not work if they are not operating in a positive environment (Kumar \& Altschuld, 2002). According to Lee and Tsai (2013), who studied the researches performed in the field of technology-aided learning in Biology education, more studies should be conducted to understand the relationships between instructional design, technology type, and the cognitive and epistemological process.

Another important factor in determining how technology might be used in education is to determine what technologies teachers or pre-service teachers (technology users) know. What technologies teachers or pre-service teachers used in the classroom environment was explored in some studies. Tarman and Baytak (2011) set forth the role of technology in education by investigating what technologies the pre-service teachers used in the social studies course. The social studies pre-service teachers included in the research by the author show programs such as PowerPoint and Office programs they use in the classroom environment as the most effective technological tools in education and instruction. In her study wherein she examined the professional competency of the pre-service information technology pre-service teachers in the instructional process, Kabakç-Yurdakul (2011) used small-group interviews, observations and field notes. The pre-service teachers included in the study by the author used computer, projector, laptop and digital camera during the introductory activities of the instructional process computer, projector, speakers and laptop during the presentation activities. In the evaluation activities during which the highest number of technological tools were used, the pre-service teachers used speakers, headphones and a microphone, along with a computer, a projector, a laptop and a digital camera. In his research, İşman (2002) examined the efficiency of the teachers at educational technologies and their cases of using educational technologies in terms of different variables. According to the overall results of this study including some 137 teachers, the teachers fail to efficiently use the newly developing educational technologies in educational and instructional environments. According to the gender variables of the study, however, male teachers use Windows, Word, PowerPoint, Excel, a printer, a laserdisc, a video camera, an audio cassette, an overhead projector and search machines more than female teachers. According to the age variable, the teachers aged below 30 years use diagrams, Mac or IBM, scanners, digital cameras, Data Show, multimedia, videos, radios, overhead projectors, the Internet, webcams, modems and the Internet systems more considerably. Taş, Özel and Demirci (2007) investigated geography teachers' perspectives on technology and their levels of benefiting from technology. According to the results of this study, the teachers stated that they knew and used the writing programs like Microsoft Office Word, the presentation programs like PowerPoint, the calculation/operation programs like Microsoft Office Excel, CDs, LCD projectors, scanners, printers, digital cameras and video cameras the most. Nevertheless, almost half of the geography teachers included in the research expressed that they knew but did not use overhead projectors and electronic announcement boards. On the other hand, the overwhelming majority of the participants expressed that they did not know, and therefore did not use, computer simulations, database programs like Access, computer programs such as Basic, $\mathrm{C}++$, Notran and Pascal, Remote Sensing programs like Erdas and GIS software programs such as ArcGIS and Map Info that are widely used in geography education. In his research, Kurt (2010) explored the use of technology at primary school level in Turkey. According to the results of the study by the author, teachers tend to use simpler technologies (e.g., TV) more than computers, if they are easily available. In their study with some 17 student teachers, 17 cooperating teachers, 5 university-level faculty, and 3 student teaching supervisors, Duran, Brunvand and Fossum (2009) examined their knowledge and skills about technology. The teachers included in the study by the authors most frequently used PowerPoint, online research, word processing, graphing organizer, Excel/graphing, video creation and image capture in the technology-based courses they conducted. In their study, 
Erdemir, Bakırcı and Eyduran (2009) aimed to determine pre-service teachers' self-confidence with respect to the use of technology in education. The research was carried out with the participation of some 325 pre-service teachers from six different departments, i.e., mathematics, science, classroom, social studies, pre-school and Turkish teaching, in the faculties of education at two different universities. According to the results of the study by the authors, the pre-service teachers did not feel efficient at using the Internet and computers for instructional purposes, while they stated that they were efficient at using search engines. In addition, the participants stated that they were able to prepare simple materials for instructional purposes but failed to prepare complex and multi-purpose instructional devices. Adigüzel (2010) explored classroom teachers' levels of using these technologies. According to the results of the study, the teachers commented that they used projectors, videos, overhead projectors and acetates the most out of the tools with a reflecting feature. Of audio-visual aids, computers, VCDs and DVDs were used the most. Nevertheless, according to the study by the author, it was concluded that the use of tools with a reflecting feature out of all instructional tools and materials, new instructional technologies like audio-visual aids and computers and computer technologies that facilitate students' learning by providing various opportunities in the teaching and learning process was rather low.

It might be stated that individuals will not be able to easily get used to those innovations if they lack of skills to use, including technology, and that they will not use them in their everyday life. In this case, it is clear that those pre-service teachers who lack adequate skills to use technology will have problems regarding its application. With a similar view, Giamalas and Nikolopoulou (2010) assume that teachers'-students' views influence their intentions and these, in turn, influence behaviour. Therefore, the determining of the cases of pre-service teachers (who will become the teachers of the future) to use technology and their views on this matter is particularly important as this will provide clues to at what level they will be able to apply these technologies in their professional life. At the same time, determining the technologies that pre-service teachers prefer to use is also considerably important in terms of finding out the technologies they lack. In this way, measures can be taken for increasing their educational level regarding limited used technologies. One other important issue is to determine for what purposes the pre-service teachers use those technologies in educational environment. In this way, the awareness of pre-service teachers regarding the purposes of use of technology can be put forth and therefore it would be easier to take the necessary measures by fulfilling their limited or lacking information on this matter.

In this case, the problem of the study can be expressed in this way: (I) Which technologies do pre-service teachers prefer to use in micro-teaching presentations? (II) For what purposes do pre-service teachers use the technologies they prefer to use in micro-teaching presentations?

\section{Method}

This research which is conducted in order to determine the technologies that pre-service science teachers prefer to use in micro-teaching practices which they present their teaching skills and their purposes of use is a qualitative research. According to Yıldırım and Şimşek (2006), qualitative studies enable one to be able to see the subject investigated from the perspective of the participating individuals and to reveal the social structure and processes forming these perspectives of the participants. It might be expressed that this research displays the features of a qualitative research as it also aims to reveal the case of pre-service teachers to use technology in detail from their perspective and to collect data directly by means of a large number of data collection tools. Of qualitative studies, the case study model was selected and used in the present research. Cohen, Manion and Morrison (2007) express a case study as a strong method of observing the impacts in real contexts. According to Marshall and Rossman (1999) case studies rely on document analysis, interviewing, and some forms of observation as data collection. A case study was used in this research since it was aimed to obtain in-depth and detailed information on the matter by means of different data collection tools such as a view form, interviews and observation notes on this matter. The research was made with the senior pre-service science teachers studying at the Department of Primary School Science Teaching in the Faculty of Education at Celal Bayar University.

\subsection{Context}

The primary school science teacher education programme is a four-year programme (eight semesters) in all education faculties in Turkey. The pre-service science teacher's sole responsibility is to teach science to their students from grades 5 to 8 after graduating from the faculty. In this programme, pre-service science education teachers are trained in three different fields, which are the field education classes (i.e., Introduction to Modern Physics and Special Matters in Biology), the teaching professional knowledge classes (i.e., Special Education Methods I-II and Class Management), and the general knowledge classes (i.e., Computer I-II and Public Service Application). In this contex it is obvious that the Special Education Methods II class performed in the research is 
a class aimed to ensure the acquisition of teacher profession knowledge by the pre-service science education teachers.

The Special Education Methods II class of the science education teacher preparation program in Turkey is provided during the fourth year of the discipline. The said class is taught in sets of 4 lessons per week with 2 of them being theoretic and 2 of them being practical lessons. According to the Higher Education Institution, the contents of the class are provided as follows: Microteaching Applications (pre-service science teachers prepare in class an education plan on subjects selected from the Science and Technology Education Programs applied in 5th-8th grades, organize the environment, tools and materials and present the lecture and their presentations are evaluated in terms of teaching knowledge and skills) (Turkish Higher Educational Council, 2014). Therefore, the technology usage mentioned in the research is carried out within the microteaching applications of the special education methods II class.

\subsection{Participant (Subject) Characteristics}

48 pre-service science teachers ( 31 females and 17 males, aged 21-23 years) participated in the microteaching applications of the research carried out in the course "Special Teaching Methods II". Table 1 provides information on the numbers of the sample of pre-service science teachers included in the process of the use of technology within the microteaching presentations, the sample of pre-service teachers whose views were obtained by using a view form when these applications were over and the sample of pre-service teachers with whom a semi-structured interview was made in order to deepen the findings again when the applications were over.

Table 1. Data on the samples and genders contained at different stages of the research

\begin{tabular}{cccc}
\hline The sample at the stage of application of the use of technology & The view form sample & The semi-structured interview sample \\
\hline 48 & 31 & 9 \\
\hline
\end{tabular}

As seen in Table 1, the applications of technology were made with the participation of a total of 48 pre-service science teachers within the scope of the course "Special Teaching Methods II". The 31 pre-service science teachers who were selected among the participants by the method of cluster sampling as a result of the applications were applied a view form consisting of open-ended questions. In addition, semi-structured interviews were made with a total of 9 people who were selected on the basis of the fundamental principle of voluntariness among the pre-service teachers who responded to the view form.

\subsection{Data Collection}

In the research, data was collected from the presentation files the pre-service teachers had prepared regarding the microteaching applications, from the instructor's observation notes on their presentations, from the view form and from the semi-structured interviews. In this context, data triangulation was carried out by using more than one data collection tool in order to enhance validity and to collect more detailed information on the subject in the present study. According to Thurmond (2001), when used appropriately, triangulation might enhance the completeness and confirmation of data in research findings of qualitative research. The benefits of triangulation can include increasing confidence in research data (Jick, 1979). Since the presentation files and instructor's observation notes through a document analysis of the technologies the pre-service teachers used during the microteaching applications, the view form concerning the use of technology and the interviews were utilized in this research, it might be stated that data triangulation was utilized in the process of data collection. In this context, the process of data collection was considered under four subtitles, namely "the process of data collection from presentation files", "the process of data collection from observation notes", "the process of data collection from the view form" and "the process of data collection from semi-structured interviews".

\subsubsection{The Process of Data Collection from Presentation Files}

In the research, data was obtained from the presentations the pre-service science teachers delivered within the scope of the microteaching applications throughout the semester. "Special Teaching Methods II", during which the applications were made, is a compulsory course provided for four hours per week. This course encompasses pre-service science teachers' preparing of a plan on the subjects selected from the science and technology instruction program applied in the grades of the middle school level and their arrangement of tools and materials and presentation of a lesson, that is to say, their performance of a microteaching application. In this context, the 
teacher pre-service teachers performed microteaching on previously determined subjects for four course hours per week. The applications were carried on in the form of group work. During these applications, the pre-service science teacher (s) that had prepared the presentation acted as a teacher, whereas the other pre-service teachers in the classroom acted as the 6th, 7th or 8th grade students, depending on the level of the subject. Following this process, the pre-service teachers were asked to prepare a file regarding the presentations they delivered in the applications. When the process was over, the different technologies the pre-service teachers used in their presentations during the microteaching applications were used as one of the data collection tools through the examination of the presentation files they had submitted.

\subsubsection{The Process of Data Collection from Observation Notes}

The presentations by the pre-service teachers throughout the semester were monitored by the instructor of the course (at the same time the author of the research) and notes were taken down regarding the applications. According to Marshall and Rossman (1999, p. 107), "The observational record is frequently referred to as field notes - detailed, nonjudgmental, concrete descriptions of what has been observed". The observation notes taken down by the instructor in the research were taken down individually for the pre-service teachers included in the groups that delivered presentations each week. When the microteaching applications were over, these observation notes were analyzed in the context of the technologies used throughout the presentations and the examples of the purposes of using these technologies. In the analyses, the groups were given codes from G1 to G16; the presentations were given codes in the form of P1 and P2; and the presentations by the groups of pre-service teachers were expressed with these codes in the research.

\subsubsection{The Process of Data Collection from the View Form}

Another data collection tool used in the research is the view form. As it was also aimed to obtain the views of pre-service science teachers about the different technologies they used in their presentations in the research, a view form that was frequently included in qualitative research was used as another data collection tool. The view form contained open-ended view questions prepared by the researcher. When preparing the open-ended questions in the present study, the studies on the subject of technology and on the development of a view form that were available in the literature were examined and the initial versions of the questions considered to be included in this research were drawn up. In order to ensure their validity, the questions prepared were presented to obtain the comments of four specialists, one in the field of computer technologies and teaching, two in the field of science education and one in the field of measurement and assessment. In line with the feedback by the specialists, some questions were excluded from the form, while some of them were corrected and included in the form. To determine the comprehensibility of the questions developed, 3 teacher pre-service teachers at two different levels-the 3rd and 4th grades-outside the sample were interviewed. In parallel with the explanations by the pre-service teachers interviewed, some words were corrected and thus the view form was finalized.

\subsubsection{The Process of Data Collection from Semi-Structured Interviews}

Another data collection tool included in the research is the semi-structured interviews. An interview is a useful way to get large amounts of data quickly and combined with observation, it allows the researcher to understand the meanings that people hold for their everyday activities (Marshall \& Rossman, 1999, pp. 108-110). A way parallel to the development of questions included in the view form was also followed at the stage of developing the semi-structured interview questions and the responses of pre-service teachers to the view form were utilized. In the interviews, the names of the pre-service teachers were kept secret; they were given codes from A to I; and their views were expressed with these codes in the study. The interviews were recorded by voice recording as well as by taking down notes by the researcher. The interviews with each pre-service teacher lasted 20 minutes on average. Following this process, the interview records were turned into texts for data analysis. Later on, these written texts were descriptively analyzed by the researcher.

\subsection{Data Analysis}

In the present research, the presentation files the pre-service science teachers had prepared for the microteaching applications and the observation notes were examined through document analysis. The uses of technology included in the presentation files were first of all classified by type and analyzed. In these analyses, the technologies included in the presentation files of the teacher pre-service teachers were considered and examined under two different themes, namely "technological tools and materials" and "applications of technological use". It can be simply explained that a projection apparatus was classified as a technological tool and material, while PowerPoint or a slide was classified as an application of technological use. The technological tools and materials contained under the first theme were marked with plus (+) and minus (-) symbols in order to determine which of them was used in the presentations of each group. The applications of technological use were indicated by 
writing their frequency of repetition in the presentations. The groups were given codes from G1 to G16 in these examinations; the order of presentations was stated as P1 or P2 and then the analyses were made. The observation notes taken down by the instructor on the presentations delivered by the students in the microteaching applications were again examined through document analysis. In these examinations, the writing about the technologies basically used by pre-service teachers was separately collected and turned into texts. By making use of these texts, examples of pre-service teachers' ways of using technology were presented in the related sections of the findings by stating the date and order of presentation (as "the 1st presentation" or "the 2nd presentation").

In the research, content analysis was utilized to analyze the data obtained from the view form. As it is known, content analysis is one of the methods used frequently in qualitative research. During the content analysis, the data obtained from the view form was examined and the themes and codes were created on the basis of this data. In the research, first of all the data obtained from the view form was encoded by two different researchers specialized in the field. During this encoding, a process of individual analysis of the data obtained from the view form and its encoding in line with a specified encoding method was followed. Later on, the similar codes were grouped and these groups were provided with common names. In this way, general categories and special subcategories, that is, themes were formed. After this arrangement, codes suitable for the content of the themes, that is, special subcategories were established. The frequency and percentage values of the expressions - codes - in the themes were found and the results were tabulated. Craig (1981), who expresses that it is essential to evaluate the reliability of encoding, suggests that this should be done so, for the reliability of individual encodings and category schemes is variable. Again when the qualitative studies wherein content analysis was used in the literature are examined, it is seen that the consistency between the encoders is generally computed to determine reliability. As it has also been expressed previously, the encodings of the content analysis were performed by two different researchers in this study too. Therefore, the consistency between the encodings of these two researchers was computed for the calculation of reliability in the study. Frick and Semmel (1978) expressed this percentage as the ratio of the number of agreements between the specialists to the sum of the numbers of agreements and disagreements. For each question, the formula concerned was used and the percentages of agreement were computed. In conclusion, the percentage of agreement for the encodings in the research was calculated. The general percentage of agreement for all questions in total was calculated as 0.88 .

The data obtained from the semi-structured interviews, another data collection tool used in the research, was analyzed with the method of descriptive analysis, again one of the analysis methods used frequently in qualitative research, and these results were presented in the section of findings. In this study as well, this feature of descriptive analysis was utilized and the results were presented in the form of direct quotations in order to reflect the views of the participants in detail and to compare them with the results obtained from the other data collection tools.

\section{Results}

The findings of the study have been examined under two main titles as "the technologies that pre-service teachers prefer to use" and "the purposes of use of technology of pre-service teachers".

\subsection{The Technologies Hat Pre-Service Teachers Prefer to Use}

Data gathered by reviewing the presentation files, notes of instructors related to student observations during the presentations, view form and semi-structured interview records after the practices have been used in order to determine the technologies that pre-service teachers prefer to use in micro-teaching practices performed for improving their teaching skills.

The results with respect to the technologies the pre-service teachers used in their presentations in the course "Special Teaching Methods II" according to the data obtained from the analysis of the view form are provided in Table 2.

Table 2. The technologies used by the pre-service teachers in the microteaching applications according to the view form

\begin{tabular}{lccc}
\hline Code & $\mathrm{f}$ & Frequency of use \%* & Sample \%** \\
\hline Computer/Laptop & 31 & 29.2 & 100.0 \\
Projection apparatus & 29 & 27.4 & 93.5 \\
\hline
\end{tabular}




\begin{tabular}{llll}
\hline Overhead projector & 15 & 14.2 & 48.4 \\
Video & 8 & 7.5 & 25.8 \\
Animation/Simulation & 6 & 5.7 & 19.4 \\
Microscope & 5 & 4.7 & 16.1 \\
Camera & 4 & 3.8 & 12.9 \\
Video camera & 3 & 2.8 & 9.7 \\
TV/Radio & 2 & 1.9 & 6.5 \\
Sound system/Microphone & 2 & 1.9 & 6.5 \\
Oscilloscope & 1 & 0.9 & 3.2 \\
\hline
\end{tabular}

*Percentage of frequency within the sum of the technologies used.

**Percentage of use for each technology according to the view form sample.

It is seen that the pre-service teachers utilized the computer technology the most when delivering their presentations. When the percentage of the sample was considered in terms of computer use, we see from the data all of the pre-service teachers who participated in the view form application benefited from this technology in their presentations. It is seen that the projection apparatus was another technology used the most by the pre-service science teachers and that $93.5 \%$ of the participants expressed that they had used this technology during the microteaching applications. According to the findings, almost half of the participants $(48.4 \%)$ state that they used an overhead projector and $25.8 \%$ of them state that they made use of videos. The pre-service teachers listed the other technologies they most frequently used as animations/simulations, microscopes, cameras and video cameras.

The data obtained by examining the semi-structured interviews with the primary school pre-service science teachers through descriptive analysis also reveals similar results. The pre-service teachers stated that they had primarily used a computer and technologies such as projection apparatuses, videos, simulations and microscopes in their presentations in the course "Special Teaching Methods II". Of the pre-service teachers interviewed on this matter, Pre-Service Teachers A commented as follows:

Interviewer: What technologies did you use during your microteaching applications in the course "Special Teaching Methods II"?

Pre-Service Teachers A: We primarily used a computer.

Interviewer: Any other?

Pre-Service Teachers A: We used simulations. We used a projection apparatus.

Interviewer: Why did you use them? Why did you prefer them?

Pre-Service Teachers A: For example, when showing the friction force, you can show it with an experiment, but it is again the computer which will describe what exactly happens there with their instructions.

On the other hand, Pre-Service Teachers C and D, who particularly related the technologies they had used in the microteaching applications to possibilities, commented on the matter as follows:

Pre-Service Teachers C: Of course, the most important one was the computer. Apart from it, we used the projection apparatus and the overhead projector. We used a camera as another technology. We could not use many things other than them. As students, we could only afford these technologies. In addition, we downloaded information from the Internet. We used the animations and slides we had downloaded from the Internet because science teaching involves a specific age group and it is necessary to make the subjects amusing. They particularly contain visual elements. We also used this dimension of technology.

Pre-Service Teachers D: We used a projection apparatus for our slide presentation. Of course, we used the laptop. Later on, we used technological tools like the video cassette for what should be transferred through sound. There are many other things, but these are the ones that come to my mind. In addition, we used them owing to the limited financial 
possibilities. We have a computer, but schools have not developed to this end yet. If electronic boards, etc. further increase in number, we will try to use them too.

Some pre-service teachers, with whom a semi-structured interview was made, stated that they preferred the technologies they had used in the microteaching applications generally according to their accessibility and their being economical and that they used them in their presentations accordingly. Pre-Service Teachers G and H, who expressed their views accordingly, commented on the matter in the following way:

Pre-Service Teachers G: We particularly made slides in our presentations. We used materials. We used an overhead projector and a projection apparatus because they were easier to access. They are more economical. They provide students with more benefits. Furthermore, it is easier for us to access them.

Pre-Service Teachers H: For example, we used the projection apparatus. We made use of the computer. I can say that we used those technologies which we could access the most at our school. We also used several technologies in our experiments. For instance, we utilized a microscope. We preferred them due to the conditions and as they were economical.

Another data collection tool used to determine the technologies used by the pre-service teachers at the Department of Science Teaching during the microteaching applications is the presentation files the participants submitted to the instructor after their presentations. The data obtained as a result of the examination of presentation files through document analysis was addressed under two main themes, namely "technological tools \& materials" and "applications of technological use". The theme of technological tools \& materials was analyzed according to whether the technological tool concerned was used in the first and the second presentations by the groups and when it was used, this was indicated with the $(+)$ mark and the results are presented in Table 3. Under the theme of applications of technological use, how frequently the technology concerned was used in the presentations delivered by the pre-service teachers was indicated with numbers and they are presented in Table 3.

Table 3. The technologies used by the pre-service teachers in the microteaching applications according to the examination of their presentation files

\begin{tabular}{|c|c|c|c|c|c|c|c|c|c|c|c|c|c|c|c|}
\hline \multirow{2}{*}{\multicolumn{2}{|c|}{$\begin{array}{l}\text { Technology used } \\
\text { Group } \\
\text { Po./ }\end{array}$}} & \multicolumn{8}{|c|}{ Technological tools and materials } & \multicolumn{6}{|c|}{ Applications of technological use } \\
\hline & & 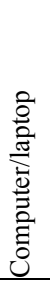 & 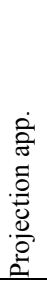 & 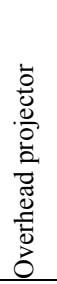 & 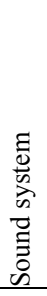 & 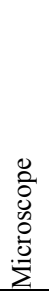 & 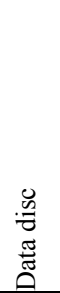 & 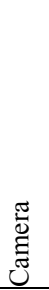 & 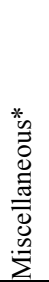 & 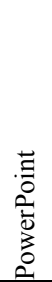 & 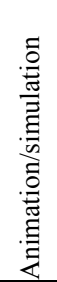 & 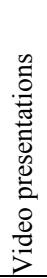 & 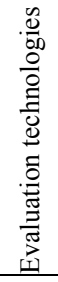 & 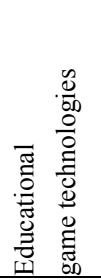 & 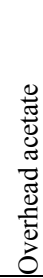 \\
\hline G1 & $\mathrm{P} 1$ & + & + & & & & + & & & 3 & 4 & & & & \\
\hline & P2 & + & + & & + & & + & + & & 3 & 1 & 4 & & & \\
\hline G2 & $\mathrm{P} 1$ & + & + & & & & + & + & & 3 & 1 & & & & \\
\hline & $\mathrm{P} 2$ & + & + & & + & & + & + & & 3 & 1 & 1 & & & \\
\hline G3 & $\mathrm{P} 1$ & + & + & & + & & + & + & & 4 & & 1 & & & \\
\hline & $\mathrm{P} 2$ & + & + & & + & & + & + & & 4 & 1 & 2 & & & \\
\hline G4 & $\mathrm{P} 1$ & + & + & + & & + & + & & & 3 & 2 & & & & 2 \\
\hline & $\mathrm{P} 2$ & + & + & & + & & + & & + & 3 & 1 & 1 & & & \\
\hline G5 & P1 & + & + & & + & & + & & & 3 & 5 & 1 & & 1 & \\
\hline & P2 & + & + & & & + & + & + & + & 3 & 1 & & & 2 & \\
\hline G6 & P1 & + & + & & + & & + & & & 3 & & 1 & & & \\
\hline & P2 & + & + & & + & & + & & & 3 & 1 & 1 & & & \\
\hline G7 & P1 & + & + & & + & & + & & & 3 & 2 & 1 & & & \\
\hline & P2 & + & + & & + & & + & & & 3 & 1 & 1 & & & \\
\hline G8 & $\mathrm{P} 1$ & + & + & & & & + & & & 3 & 2 & & & & \\
\hline & P2 & + & + & & & & + & & & 3 & & & & & \\
\hline G9 & P1 & + & + & & + & & + & + & & 3 & & 1 & & & \\
\hline & $\mathrm{P} 2$ & + & + & & + & & + & + & & 3 & & 2 & & 1 & \\
\hline
\end{tabular}




\begin{tabular}{|c|c|c|c|c|c|c|c|c|c|c|c|}
\hline \multirow[t]{2}{*}{ G10 } & P1 & + & + & + & + & + & & 3 & & 2 & \\
\hline & $\mathrm{P} 2$ & + & + & & + & & & 3 & 3 & & \\
\hline \multirow[t]{2}{*}{ G11 } & P1 & + & + & + & + & + & + & 3 & 1 & 3 & \\
\hline & P2 & + & + & & + & + & & 3 & 1 & & \\
\hline \multirow[t]{2}{*}{ G12 } & $\mathrm{P} 1$ & + & + & & + & & & 2 & 1 & & 1 \\
\hline & $\mathrm{P} 2$ & + & + & & + & & & 2 & & & \\
\hline \multirow[t]{2}{*}{ G13 } & $\mathrm{P} 1$ & + & + & + & + & + & & 3 & & 3 & \\
\hline & $\mathrm{P} 2$ & + & + & + & + & + & & 3 & 1 & 2 & \\
\hline \multirow[t]{2}{*}{ G14 } & $\mathrm{P} 1$ & + & + & + & + & + & & 3 & 5 & 3 & 1 \\
\hline & P2 & + & + & + & + & & & 3 & & 7 & \\
\hline \multirow[t]{2}{*}{ G15 } & P1 & + & + & + & + & + & + & 3 & 1 & 2 & \\
\hline & $\mathrm{P} 2$ & + & + & + & + & + & & 3 & 4 & 6 & 1 \\
\hline \multirow[t]{2}{*}{ G16 } & $\mathrm{P} 1$ & + & + & + & + & & & 3 & 1 & 1 & \\
\hline & $\mathrm{P} 2$ & + & + & + & + & & & 3 & & 3 & \\
\hline
\end{tabular}

* On the other hand, a video camera, an oscilloscope, a microphone and a radio/cassette player were used by a group of pre-service teachers in the section entitled "Miscellaneous".

**In the Table, "G" denotes the group number and "P" the presentation number.

It is understood that while the pre-service teachers were delivering their presentations, all of the groups used a computer or a laptop and a projection apparatus as technological tools \& materials in both their first and second presentations. Additionally, all of the pre-service teachers added a $\mathrm{CD}$ of the presentations they had prepared to their presentation files and they used data discs in the use of videos, PowerPoint, educational software, Office documents, photographs and such visual elements in their presentations. Apart from them, according to their files, it is seen that the sound system is another technological tool \& material the pre-service teachers most frequently used. Besides, it is apparent that the pre-service teachers used a camera, an overhead projector and a microscope. It is seen that all of the pre-service teachers used PowerPoint as their applications of technological use both in their first and second presentations. It is seen that animations and simulations were used in 22 of a total of 32 presentations throughout the applications. According to the files of the pre-service teachers, it is seen that another technological application used the most is the video presentations. Apart from them, according to the presentation files examined, some of the pre-service teachers used evaluation technologies such as concept maps and structured grids or educational game technologies prepared on the computer.

The instructor's observations were utilized to better understand what kinds of technologies were used at which stage in the process of these activities. It is understood that one of the most used technologies is animations. Animations were particularly used in the lecturing process, to ensure making an association with everyday life, and in the process of realizing the activities. Following are two of the instructor's observation notes on the use of animations in the lecturing process:

An animation that was convenient for the unit "reproduction, growth and development in living things" was used as one of the presentation activities in the lecturing process (The observation note on the 1st presentation by Student 44, dated October 13).

The experiment to find the factors that affected the pressure of liquids was presented to the students by means of an animation (The observation note on the 2nd presentation by Student 21, dated December 8).

Another technology most widely used by the pre-service teachers was the computer-aided photograph and/or image display. It is seen that the use of this technology widely took place in the lecturing process or in the associating of the subjects with everyday life. Following are two of the instructor's observation notes on the use of computer-aided photographs and/or images to associate the subject with everyday life:

Towards the end of the presentation, he gave examples by showing images/photographs (e.g., the broken glass pieces left on the ground when one goes for a picnic) that associated the subject with everyday life on the computer (The observation note on the 1st presentation by Student 3, dated October 27).

She showed photographs and images by the help of a projection apparatus in order to make an association with everyday life (about how igloos are heated) (The observation note on the 1 st presentation by Student 13, dated November 10). 
Videos are one of the technologies the pre-service teachers used the most during their presentations in the microteaching applications. The pre-service teachers showed the videos of some experiments on the subject. Here is one of the instructor's observation notes on the use of videos when displaying the experiment:

Several experiments concerning electrification by friction were presented by video displays

(The observation note on the 1st presentation by Student 38, dated November 03).

It was determined that the pre-service teachers benefited from documentary film and simulation in their presentation activities. Here is one of the instructor's observation notes on the matter:

She showed a computer simulation about solid, liquid \& gas (The observation note on the 1st presentation by Student 11, dated November 02).

According to the instructor's observation notes, it is understood that the pre-service teachers utilized the sound system technology the most in their presentations. Following is one of the instructor's observation notes on the matter:

Attention was attracted by making the students listen to a song about the subject of "matter" and the lesson was initiated in this way (The observation note on the 2nd presentation by Student 47, dated December 8).

The pre-service teachers used a microscope during their presentations. Here is one of the instructor's observation notes on the use of a microscope:

The phases of meiosis were examined under a microscope (The observation note on the 2 nd presentation by Student 38, dated December 29).

According to the instructor's observation notes, the pre-service teachers also used a video camera and an oscilloscope in their presentations within the scope of the microteaching applications. The instructor's observation note on the use of an oscilloscope is as follows:

An oscilloscope was shown to the students and used (The observation note on the 2nd presentation by Student 4, dated December 22).

\subsection{The Purposes of Use of Technology of Pre-Service Teachers}

Findings regarding the purposes of use of technologies that pre-service teachers prefer to use while presenting their teaching skills have been generated by using the view form, semi-structured interviews and observation notes of instructors. The responses of the participants to the question contained in the view form regarding the purposes for their use of technology were analyzed with content analysis and the obtained data is presented in Table 4.

Table 4. The views of pre-service teachers about the purposes for the technologies they used in the microteaching applications according to the view form

\begin{tabular}{|c|c|c|c|c|c|c|c|c|c|c|c|c|c|}
\hline Themes & Codes & 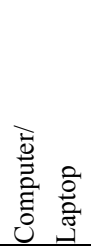 & 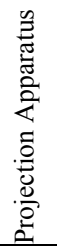 & 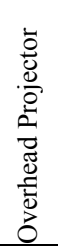 & $\stackrel{8}{i}$ & 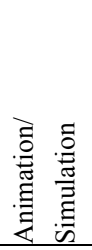 & 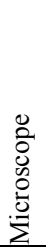 & 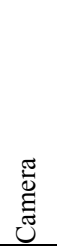 & 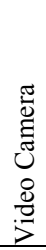 & 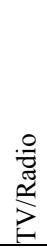 & 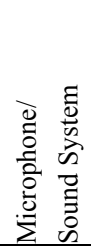 & $\begin{array}{l}0 \\
0 \\
0 \\
0 \\
0 \\
0 \\
\overline{0} \\
0 \\
0\end{array}$ & हँّ \\
\hline \multirow{6}{*}{$\begin{array}{l}\text { Contribution } \\
\text { to the gains } \\
\text { of the course }\end{array}$} & $\begin{array}{l}\text { To enhance the comprehensibility of the } \\
\text { subject }\end{array}$ & 3 & 4 & 3 & & 1 & 1 & & & & 1 & & 14 \\
\hline & To concretize abstract subjects & 3 & 2 & 1 & & & 1 & & & 1 & & & 8 \\
\hline & To facilitate learning & & 1 & 1 & & & & & & & & & 2 \\
\hline & To ensure significant learning & 1 & 1 & & & & & & & & & & 2 \\
\hline & To make an association with everyday life & & & & 1 & & & & & & & & 1 \\
\hline & To ensure permanence & & & 1 & & & & & & & & & 1 \\
\hline \multirow{5}{*}{$\begin{array}{l}\text { Contribution } \\
\text { to the } \\
\text { learning } \\
\text { environment }\end{array}$} & To ensure visuality & 4 & 3 & & 1 & 1 & 1 & 1 & & & & & 11 \\
\hline & To attract attention/interest & 2 & 1 & 1 & 1 & & 1 & & & & & & 6 \\
\hline & To address more than one sense & 1 & 1 & 1 & & 1 & & & & & 1 & & 5 \\
\hline & To ensure being both visual and audio & 1 & 2 & & & & & & & & & & 3 \\
\hline & To be amusing & & & & 1 & 1 & & & & & & & 2 \\
\hline
\end{tabular}




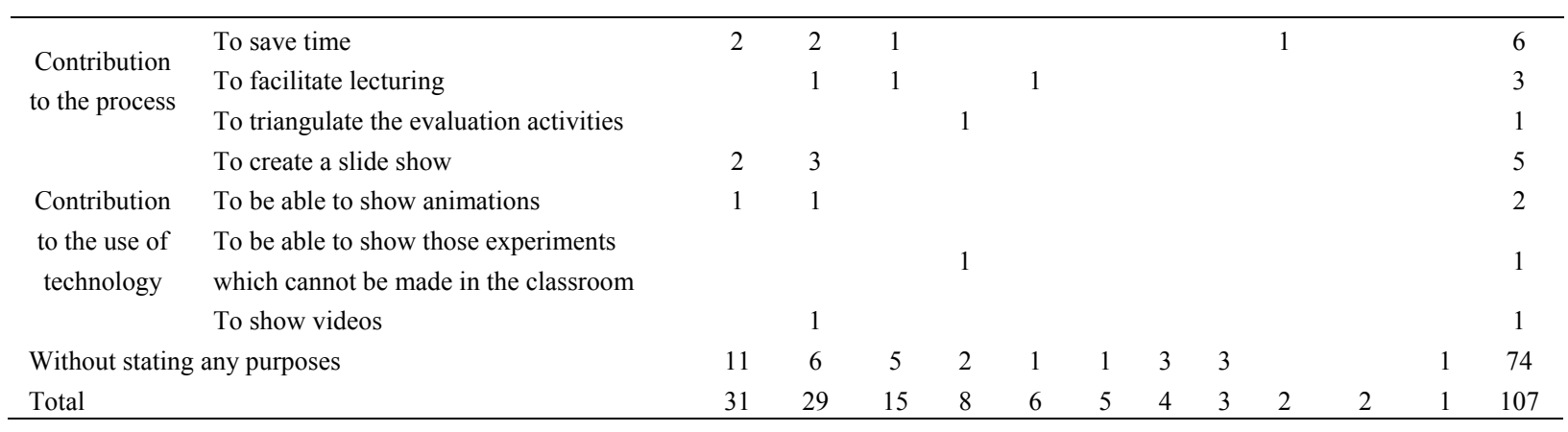

It is seen that the views of pre-service teachers about their purposes for using technology were collected under four themes, namely "contribution to the gains of the course", "contribution to the learning environment", "contribution to the process" and "contribution to the use of technology". The pre-service teachers stated that they used technology the most because it contributed to the gains of the course ( $\mathrm{f}=28)$ and to the learning environment $(\mathrm{f}=27)$. It is understood that to enhance the comprehensibility of the subject was the purpose repeated the most by the participants under the theme "contribution to the gains of the course", while to ensure visuality was the most repeated purpose under the theme "contribution to the learning environment". The pre-service teachers were of the opinion that making use of computers, projection apparatuses and overhead projectors particularly enhanced the comprehensibility of the subject. In addition, the pre-service teachers stated that these technologies were effective on the concretization of abstract subjects $(\mathrm{f}=8)$. Furthermore, the participants stated that they used technologies such as computers, projection apparatuses, videos, animations, simulations and microscopes in their presentations generally in order to ensure visuality $(\mathrm{f}=11)$, to attract attention/interest $(\mathrm{f}=6)$ and to address more than one sense $(\mathrm{f}=5)$. According to the views of the pre-service teachers, the use of technologies such as computers, projection apparatuses and overhead projectors saved time during the presentations $(\mathrm{f}=6)$ and facilitated lecturing $(\mathrm{f}=3)$. Moreover, the use of a projection apparatus allows creating a slide show and can show animations and videos. One of the participants was of the opinion that making use of the video technology in their presentations provided an opportunity of showing those experiments which could not be made in the classroom.

The descriptive analyses of the semi-structured interviews with the pre-service teachers are also greatly parallel to their views on the purposes for the use of technology. The pre-service teachers stated that they used different technologies in the presentations they delivered in the course "Special Teaching Methods II" generally in order to ensure visuality and to enhance the comprehensibility of the subject. Of the pre-service teachers interviewed to this end, Pre-Service Teacher B commented as follows:

Interviewer: What are the purposes for your use of technology in your microteaching applications in the course "Special Teaching Methods II"? Why did you prefer these technologies? Will you please explain the purpose for the use of them?

Pre-Service Teacher B: We used a computer and a projection apparatus to enhance visuality and the comprehensibility of the subject.

On the other hand, some pre-service teachers, with whom a semi-structured interview was made, associated the purposes for their use of technology in their presentations with the features of students' age period and explained them as "to attract interest/attention" and "to address more sense organs". Pre-Service Teacher F and I, who expressed their views accordingly, commented on the matter in the following way:

Pre-Service Teacher F: Primary school students are children at playing age in terms of periods. Therefore, slide and video displays as well as animations attract their attention. We thought that when they attracted their attention, they would listen and understand better.

Pre-Service Teacher I: In instruction, the more sense organs we address and the more we use multiple intelligences, the better it is. Thanks to the technologies we use, both hearing and seeing or all of them happen altogether. I think instruction will be better if we attract the attention of students in many aspects.

Findings regarding the observation notes of instructors which have been used in determining the purposes of use of technology of pre-service teachers during their presentations have been shown in Table 5 . 
Table 5. Purposes of use of technology of pre-service teachers in their micro-teaching practices according to the instructor observation notes

\begin{tabular}{|c|c|c|c|c|c|c|c|c|c|c|c|c|c|c|}
\hline Themes & Codes & 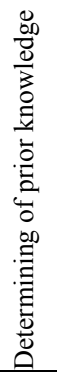 & 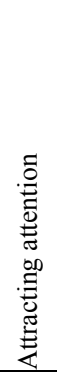 & 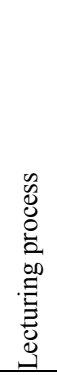 & 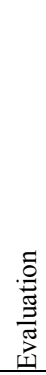 & 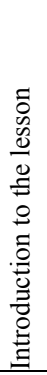 & 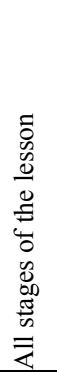 & 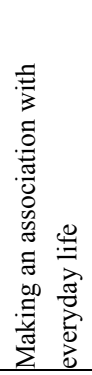 & 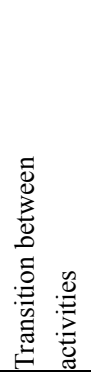 & 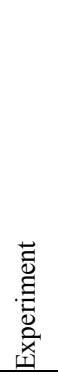 & 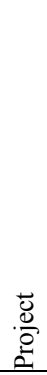 & 总 & 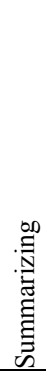 & 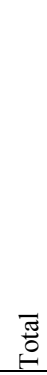 \\
\hline \multirow{8}{*}{$\begin{array}{l}\text { Presentation } \\
\text { activities }\end{array}$} & Animation display & & & 38 & & & & 8 & 2 & 2 & & 6 & & 56 \\
\hline & $\begin{array}{l}\text { Computer-aided } \\
\text { photograph/image display }\end{array}$ & & & 28 & & & & 18 & & & 2 & & & 48 \\
\hline & Slide presentation & 2 & & 7 & 1 & & 31 & & & & & & & 41 \\
\hline & $\begin{array}{l}\text { Presentation of a video } \\
\text { display }\end{array}$ & & & 29 & & & & 1 & 5 & 4 & 2 & & & 41 \\
\hline & Computer-aided activity & 2 & & 4 & & & & & & & & 3 & 2 & 11 \\
\hline & Documentary film display & & & 3 & & & & 2 & 1 & & & & & 6 \\
\hline & Simulation display & & & 4 & & & & & & & & & & 4 \\
\hline & Software program & & & & & & 1 & & & & & & & 1 \\
\hline \multirow{5}{*}{$\begin{array}{l}\text { Introductory } \\
\text { activities }\end{array}$} & $\begin{array}{l}\text { Computer-aided } \\
\text { photograph/image display }\end{array}$ & 1 & 15 & & & 6 & & & & & & & & 22 \\
\hline & $\begin{array}{l}\text { Presentation of a video } \\
\text { display }\end{array}$ & 2 & 9 & & & 9 & & & & & & & & 20 \\
\hline & Animation display & 1 & 4 & & & 3 & & & & & & & & 8 \\
\hline & Simulation display & & & & & 2 & & & & & & & & 2 \\
\hline & Documentary film display & & 2 & & & & & & & & & & & 2 \\
\hline \multirow{7}{*}{$\begin{array}{l}\text { Evaluation } \\
\text { activities }\end{array}$} & $\begin{array}{l}\text { Computer-aided } \\
\text { photograph/image display }\end{array}$ & & & & & & & & & & & & 22 & 22 \\
\hline & Animation display & & & & & & & & & & & & 11 & 11 \\
\hline & $\begin{array}{l}\text { Presentation of a video } \\
\text { display }\end{array}$ & & & & 4 & & & & & & & & 2 & 6 \\
\hline & $\begin{array}{l}\text { Technology-enhanced } \\
\text { structured grid }\end{array}$ & & & & 3 & & & & & & & & & 3 \\
\hline & $\begin{array}{l}\text { Computer-based } \\
\text { educational game }\end{array}$ & & & & 2 & & & & & & & 1 & & 3 \\
\hline & Simulation display & & & & 1 & & & & & & & & & 1 \\
\hline & Documentary film display & & & & & & & & & & & & 1 & 1 \\
\hline \multirow{7}{*}{$\begin{array}{c}\text { Technology- } \\
\text { based tool } \\
\text { activities }\end{array}$} & Use of a sound system & & 3 & 8 & & 3 & & 2 & & & & & 3 & 19 \\
\hline & Use of a data disc & & & 4 & & 4 & & & 2 & & 1 & & 1 & 12 \\
\hline & $\begin{array}{l}\text { Use of an overhead } \\
\text { projector }\end{array}$ & 1 & & 5 & 1 & & & 2 & & & & & 1 & 10 \\
\hline & $\begin{array}{l}\text { Examination by a } \\
\text { microscope }\end{array}$ & & & 4 & & & & & & 1 & & 1 & & 6 \\
\hline & Use of a video camera & & & 1 & & & & 1 & & & & & & 2 \\
\hline & The use of a camera & & & & & & & 1 & & & & 1 & & 2 \\
\hline & Use of an oscilloscope & & & 1 & & & & & & & & & & 1 \\
\hline
\end{tabular}

The presentations by the pre-service teachers were examined descriptively in line with the instructor's observation notes and it was seen that they were collected under four main themes as "presentation activities", "introductory activities", "evaluation activities" and "technology-based tool activities". When the theme of presentation activities is considered, it is understood that one of the most used technologies is animations. 
Animations were particularly used to ensure making an association with everyday life, and in the process of realizing the activities, and a transition between the activities, and for the presentation of an experiment. Here is one of the instructor's observation notes on the matter:

She used an animation about the duties of the white blood cells and, by utilizing this, asked every group to write and play a drama (The observation note on the 1st presentation by Student 16, dated November 10).

According to the analysis of the instructor's observation notes, the pre-service teachers used photographs and images twice during their presentations in order to assign project assignments to the students. Here is one of the instructor's observation notes on the matter:

The students were shown various fruit photographs on the computer and then the groups were assigned project assignments for research through the question of which elements were contained in these fruits (The observation note on the 2nd presentation by Student 47, dated December 8).

As it is also seen in Table 5, the pre-service teachers delivered slide presentations for 41 times during all their presentations. It is seen that the slides were generally used at all stages of the lesson. In other words, slides have been used by pre-service teachers for many different purposes during the teaching process, especially for the purpose of finding out preliminary information. Following is one of the instructor's observation notes on the matter:

Slides were used throughout the whole lecturing process; however, some slides contain very long and illegible writings (The observation note on the 1st presentation by Student 35, dated October 13).

According to the instructor's observation notes, videos were used for 29 times in the lecturing process, for 5 times in transitions between the activities and for 4 times in relation to the experiments.

An experimental display on how to make a light bulb was presented by a video (The observation note on the 2nd presentation by Student 34, dated December 29).

Videos were used twice by the pre-service teachers in the process of assigning project assignments about the subject to the students. Some of the instructor's observation notes on the matter are as follows:

He first showed the students a video about the subject and, by making use of this display, assigned project assignments to the groups (The observation note on the 1st presentation by Student 48, dated November 03).

A video about how to make a telescope was shown and, by utilizing this video, she assigned the project assignment of making a telescope to the students (The observation note on the 2 nd presentation by Student 43, dated December 22).

We see that computer-aided activities constituted another technology used by the pre-service teachers in their presentation activities. It is understood that these activities were used for 4 times in the lecturing process, twice in determining the prior knowledge, for 3 times in performing the activities and twice in summarizing. Following are two of the instructor's observation notes on the computer-aided activities:

He performed an activity of finding the mistakes in the text on the computer by reflecting it by the help of a projection apparatus (The observation note on the 1st presentation by Student 33, dated November 03).

She made an introduction to the lesson through a computer activity to determine the prior knowledge and asked the students questions about the unit "atomic structure of matter" (The observation note on the 1st presentation by Student 11, dated November 02).

During the presentation activities that lasted a semester, a software program was used once at all stages of the lesson by the pre-service teachers. Following is the instructor's observation note on the use of this technology:

"The sky observation program" was used from time to time at all stages of the lesson (The observation note on the 2nd presentation by Student 39, dated December 22).

As it is also seen in Table 5, it is understood that the pre-service teachers made use of technology in the introductory activities in order to determine the prior knowledge, to attract attention and to be able to make an introduction that was suitable for the lesson. It is seen that the pre-service teachers most widely used computer-aided photograph and/or image displays in the introductory activities. The pre-service teachers used 
photographs and/or images to attract attention in the introductory activities the most. Another introductory activity technology the participants most widely used was videos. Videos were used for a total of 20 times, for 9 times to attract attention, for 9 times for an introduction to the lesson and twice to determine the prior knowledge, in the introductory activities. Following are some of the instructor's observation notes on the matter:

A video about sperm and ovum was watched at the introduction to the lesson (The observation note on the 1st presentation by Student 36, dated October 13).

She showed a video about the subject of light and asked questions to inspect the prior knowledge of the students (The observation note on the 2 nd presentation by Student 46 , dated December 22).

He aimed to attract attention by showing a video about noise pollution (The observation note on the 2 nd presentation by Student 45 , dated December 25).

The pre-service teachers also made use of animations, simulations and documentary film displays in the introductory activities. While animations were generally used either to attract attention or to make an introduction that was suitable for the lesson, simulations were used twice at the introduction to the lesson. The documentary film display, another technology used in the introductory activities, was used twice to attract attention.

According to the observation notes by the instructor, it is seen that computer-aided photograph/image displays were used the most as the evaluation activities. It is comprehended that photographs and images were used for 22 times for summarizing during the evaluation activities. Apart from this, it is seen that animation and video displays were the other most widely used technologies in the evaluation activities. Animations were used for summarizing, whereas videos were generally used for evaluation. Furthermore, computer-aided structured grids were used for 3 times for evaluation, while computer-based educational games were utilized twice. Following is one of the instructor's observation notes on the matter:

He used a computer game about physical and chemical changes (The observation note on the 1st presentation by Student 20, dated November 02).

The simulation display was used once by the pre-service teachers for evaluation. Here is the instructor's observation note on the matter:

He made an evaluation by means of a computer simulation about the subject of "floating \& sinking" in science and technology (The observation note on the 2nd presentation by Student 10, dated December 8).

It is understood that the pre-service teachers utilized the sound system technology the most in their presentations under the theme of technology-based tool activities. It is seen that the sound system was used in the lecturing process, to attract attention and at the introduction to the lesson the most. Furthermore, it might be expressed that the sound system was utilized twice in making an association with everyday life, once to determine the prior knowledge and once for evaluation. Following are some of the instructor's observation notes on the matter:

He made the students listen to a song about the excretory system (The observation note on the 2nd presentation by Student 20, dated December 15).

She showed a video with a song about "Cell" (The observation note on the 2nd presentation by Student 14, dated December 15).

The use of data discs and overhead projectors constituted the other themes used by the pre-service teachers under the same theme. It is understood that apart from them, the pre-service teachers used a microscope for 6 times during their presentations. Here is one of the instructor's observation notes on the use of a microscope:

"Elodea" and "an onion skin" were examined under a microscope (The observation note on the 2nd presentation by Student 14, dated December 15).

\section{Discussion}

In the present research, the pre-service teachers expressed that they used computers, projection apparatuses, overhead projectors, videos, animations, simulations and microscopes the most in their microteaching applications. The results of analyses of the presentation files of pre-service teachers and the instructor's observation notes also reveal similar results and it is seen that all of the pre-service teachers included in the research used a computer in all the presentations they delivered. It might be stated that today computers or other computer-related technologies are more intensively used than the other technologies, with their features such as 
accessibility, the ability to serve different purposes and the ability to transform much information into different forms in a short period of time. According to Hannafin and Land (1997), recent advances in computer and related technologies have facilitated the management of electronic resources, making student-centered alternatives both possible and feasible. In this research, the frequent use of technologies such as videos, animations and simulations by the pre-service teachers may be associated with the content of the course, in which the microteaching applications were performed, that is to say, with the fact that it was a science and technology course. The science and technology course involves numerous abstract concepts (e.g., energy and heat) and micro- (e.g., atom, gene and molecule) and macro-systems (e.g., the solar system and the universe). It is also quite associated with everyday life. May be at every moment of our life, we may see an example of physics, chemistry or biology constituting the content of the science and technology course. In this context, it might be stated that technologies such as videos, animations and simulations concretize the concepts of science, exemplify them, visualize the micro- and macro-systems and allow their instruction in different ways. In addition, in the laboratory-based science and technology course, some experiments cannot be made due to the unavailability of sufficient materials or their being dangerous. In such cases, the experiment can be easily displayed to the students through technologies such as animations and simulations. As Fies and Longman (2011) have noted, "in the case of science, simulations allow experimentation with concepts and processes that cannot normally be directly observed or acted on and in turn allow students to hypothesize, observe, and reflect on their observations". Physics, biology, and chemistry, in which animations are extensively used in different ways (Lin \& Dwyer, 2010). Kozma and Russell (2005) found that web-based interactive animations helped students understand difficult and abstract concept associated with some related concept in chemistry, and aided students' understanding of molecular and dynamic concepts in laboratory experiments. They also suggested that molecular models, simulations and animations could aid in studying chemistry in general (quoted in Frailich, Kesner, \& Hofstein, 2009). With a similar view, Özmen (2004) also says that technology-enhanced education is particularly a useful method of concretizing abstract concepts of science and of providing students with rich learning activities.

According to the examination of the presentation files that were used as another data collection tool in the research, it is understood that the pre-service teachers used evaluation technologies, such as concept cartoons and structured grids, and educational game technologies in the microteaching applications. Since it may be stated that technology-based evaluations might save time as compared to classical paper-and-pencil tests, that the results can be easily recorded and analyzed when desired and that they are outstanding, the preference of these applications of technological use by the pre-service teachers may be regarded as an essential gain because the evaluation techniques concerned are the evaluations that are also called alternative evaluation techniques and used in process evaluation applications. When it is considered that the science and technology instruction program also emphasizes the use of process evaluation, it might be expressed that these applications of technological use will provide pre-service teachers with an essential professional gain.

The pre-service teachers included in the research expressed that they primarily used technology to enhance the comprehensibility of the subject, to concretize abstract subjects, to ensure visuality and to save time. Apart from them, the pre-service teachers gave many purposes such as the facilitating of learning and lecturing, the providing of significant learning, the attracting of attention and the addressing of many senses. When the purposes for the use of technology by the participants are analyzed in this context, it might be stated that they not only regarded technology as an instructional tool but also perceived it as a method or strategy that supported instruction. According to the results of the study by Tarman and Baytak (2011) with the pre-service teachers who studied in the field of social studies, some of the participants perceived technology only as a tool that positively affected education, whereas some of them perceived it as an effective instructional strategy. According to Smolin and Lawless (2011), technology has the potential to expand learning in ways. With respect to the impact of technology on the concretization of concepts, Hannafin and Land (1997) commented: "Technology-enhanced, student-centered learning environments often facilitate understanding of abstract concepts via concrete experience". The pre-service teachers included in the study by Chay, Wong and Gao (2009) showed confidence in their technology skills and felt that integrating technology would enhance their students' learning experiences. Also according to the views of the pre-service teachers at the department of classroom teaching included in the study by Yavuz and Coşkun (2008), the use of technological tools and materials in courses has many benefits. According to the pre-service teachers included in the study by the authors, the common technological tools and materials used in the field of education include devices such as computers, overhead projectors, projection apparatuses, televisions, DVDs, VCDs, microscopes, slide machines and tape recorders. In the study, positive ideas were determined, namely that lessons were made more enjoyable with these tools and materials, that they were beneficial to the comprehension of subjects, that comprehension was facilitated by using visual shows 
when conveying information and that they saved time. According to the results of the study by Taş, Özel and Demirci (2007) with geography teachers, technology-enhanced education provided diversity of instructional methods, increased diversity of the use of resources, made education more efficient and provided an opportunity of using time more effectively. In this case, it might be stated that the views of the pre-service science teachers included in this study about the use of technology resemble the views of the pre-service teachers at the department of classroom teaching included in the study by Yavuz and Coşkun and the views of the teachers included in the study by Taş, Özel and Demirci.

It is seen that the opinions of the pre-service teachers included in the study about the technologies likely to be used as instructional tools in science and technology courses are the same as the technologies they used in the microteaching applications except for SMART boards, e-books and some laboratory equipment/materials. In this case, it might be inferred that the pre-service teachers did not have much knowledge about the technologies likely to be used. Furthermore, it is seen that the pre-service teachers included in the research did not adequately use the scientific terms concerning technology or concerning technological tools. When all responses of the students to the questions contained in the view form are taken into consideration, it is understood that the pre-service teachers did not make any distinction between the tools and materials required for the use of technology (e.g., projector and digital video camera) and the different applications of technology (e.g., animation and simulation) and that they described all of them as the use of technology. Likewise, as also seen in the findings of the semi-structured interviews, the pre-service teachers use PowerPoint and a projector as if they were synonymous. However, while a projector is an instrument, PowerPoint is the software that can be presented by the help of this instrument. In this case, it might be stated that the pre-service teachers had some problems with the basic concepts about the technologies used in the classroom environment.

\section{Conclusions}

When all the results obtained from the research are taken into consideration, it is seen that the pre-service teachers used technology in the lessons for many purposes and commented that technology should be used in lessons. It is quite essential to use appropriate technological products (computers, the Internet, overhead projectors, etc.) in the course contents in those faculties which train teachers and to train the pre-service teachers with qualifications in this period. Stobaugh and Tassell (2011) reported that in the higher education classroom needs to be a focus on technology-enhanced learning strategies and instructors can explore the benefits of implementing strategies that activate learning via technology. According to Şenel and Gençoğlu (2003), successive independent technology education courses should be included from the primary school stage to the higher education stage. The authors express the training of those pre-service teachers who know, understand, love and apply technology as the basic requirement for conscious technology education. In this context, it might be suggested to make activities that will provide pre-service teachers with an opportunity of using technology primarily in method courses and in the courses included in the instructional programs at university.

Another result obtained from the research is that the pre-service teachers had some problems in properly naming the concepts of technology when expressing their opinions. It might be stated that this is related to the concept of technology literacy. Therefore, it might be recommended that pre-service teachers be provided with courses with respect to the naming of technological concepts and the scope of educational technologies regardless of branches. It might also be recommended to make a comprehensive research in order to clearly understand what the case on this matter is at different branches and to determine the technology literacy of the pre-service teachers at different branches.

A teacher's belief in the benefits of the use of educational technologies will facilitate his/her use of these technologies in the classroom environment and his/her gaining of the skills required to this end. In this context, it might be inferred that similarly, the belief of pre-service teachers studying at the university before teaching in the benefits of the use of technology will enable them to use the technologies concerned more in their professional life and to develop their skills regarding this. When the results obtained from the research are also taken into account and by considering that the attitudes of pre-service teachers towards the use of technology in courses might affect their levels of using these technologies, it might be suggested to make a long-term longitudinal research and put forward the relationship between them. 


\section{References}

Adigüzel, A. (2010). The status of instructional technology in the primary schools and classroom teachers' level of using these technologies. University of Dicle Journal of Ziya Gökalp Education Faculty, 15, 1-17.

Akcaoglu, M., Gumus, S., Bellibas, M. S., \& Boyer, D. M. (2015). Policy, practice, and reality: Exploring a nation-wide technology implementation in Turkish schools. Technology, Pedagogy and Education, 24(4), 477-491. https://doi.org/10.1080/1475939X.2014.899264

Bell, F. (2011). Connectivism: Its place in theory-informed research and innovation in technology-enabled learning. International Review of Research in Open and Distance Learning, 12(3), 98-118. https://doi.org/10.19173/irrodl.v12i3.902

Campbell, T., \& Abd-Hamid, N. H. (2013). Technology Use in Science Instruction (TUSI): Aligning the integration of technology in science instruction in ways supportive of science education reform. Journal of Science Education and Technology, 22(4), 572-588. https://doi.org/10.1007/s10956-012-9415-7

Chay, D., Wong, A. F. L., \& Gao, P. (2009). Student teachers' intentions and actions on integrating technology into their classrooms during student teaching: A Singapore study. Journal of Research on Technology in Education, 42(2), 175-195. https://doi.org/10.1080/15391523.2009.10782546

Cohen, L., Manion, L., \& Morrison, K. (2007). Research methods in education (6th ed.). London: Routledge Falmer.

Craig, R. T. (1981). Generalization of Scott's index of intercoder agreement. Public Opinion Quarterly, 45, 260-264. https://doi.org/10.1086/268657

Duran, M., Brunvand, S., \& Fossum, P. R. (2009). Preparing science teachers to teach with technology: Exploring a K-16 networked learning community approach. The Turkish Online Journal of Educational Technology, 8(4), 21-42.

Erdemir, N., Bakırc1, H., \& Eyduran, E. (2009). Determining of student teachers' self-confidence using technology in instruction. Journal of Turkish Science Education, 6(3), 99-108.

Fies, C., \& Longman, J. (2011). Bridging worlds: Measuring learners' discursive practice in a partsim supported biology lesson. International Journal of Science and Mathematics Education, 9(6), 1415-1438. https://doi.org/10.1007/s10763-010-9271-y

Frailich, M., Kesner, M., \& Hofstein, A. (2009). Enhancing students' understanding of the concept of chemical bonding by using activities provided on an interactive website. Journal of Research in Science Teaching, 46(3), 289-310. https://doi.org/10.1002/tea.20278

Frick, T., \& Semmel, M. I. (1978). Observer agreement and reliabilities of classroom observational measures. Review of Educational Research, 48(1), 157-184. https://doi.org/10.3102/00346543048001157

Giamalas, V., \& Nikolopoulou, K. (2010). In-service and pre-service early childhood teachers' views and intentions about ICT use in early childhood settings: A comparative study. Computers \& Education, 55, 333-341. https://doi.org/10.1016/j.compedu.2010.01.019

Gunduz, Ş., \& Odabasi, F. (2004). The importance of instructional technologies and material development course at pre-service teacher education in information age. The Turkish Online Journal of Educational Technology, 3(1), 43-48.

Hannafin, M. J., \& Land, S. M. (1997). The foundations and assumptions of technology-enhanced student-centered learning environments. Instructional Science, 25, 167-202. https://doi.org/10.1023/A:1002997414652

İşman, A. (2002). Efficiency of the teachers in Sakarya at educational technologies. The Turkish Online Journal of Educational Technology, 1(1), 72-91.

Jick, T. D. (1979). Mixing qualitative and quantitative methods: Triangulation in action. Administrative Science Quarterly, 24(4), 602-611. https://doi.org/10.2307/2392366

Kabakç1-Yurdakul, I. (2011). An evaluate case study on professional competency of preservice information technology teachers. The Turkish Online Journal of Educational Technology, 10(3), 33-53.

Keeler, C. G. (2008). When curriculum and technology meet: Technology integration in methods courses. Journal of Computing in Teacher Education, 25(1), 23-30. 
Koh, J. H. L. (2011). Computer skills instruction for pre-service teachers: A comparison of three instructional approaches. Computers in Human Behavior, 27, 2392-2400. https://doi.org/10.1016/j.chb.2011.08.002

Kumar, D. D., \& Altschuld, J. W. (2002). Complementary approaches to evaluation of technology in science education. Journal of Science Education and Technology, 11(2), 179-191. https://doi.org/10.1023/A:1014621631205

Kurt, S. (2010). Technology use in elementary education in Turkey: A case study. New Horizons in Education, $58(1), 65-76$.

Lee, S. W. Y., \& Tsai, C. C. (2013). Technology-supported learning in secondary and undergraduate biological education: Observations from literature review. Journal of Science Education and Technology, 22(2), 226-233. https://doi.org/10.1007/s10956-012-9388-6

Lee, Y., \& Lee, J. (2014). Enhancing pre-service teachers' self-efficacy beliefs for technology integration through lesson planning practice. Computers \& Education, 73, 121-128. https://doi.org/10.1016/j.compedu.2014.01.001

Lin, H., \& Dwyer, F. M. (2010). The effect of static and animated visualization: A perspective of instructional effectiveness and efficiency. Educational Technology Research and Development, 58(2), 155-174. https://doi.org/10.1007/s11423-009-9133-x

Marshall, C., \& Rossman, G. B. (1999). Designing qualitative research. United States of America: Sage Publications.

Niess, M. L. (2005). Preparing teachers to teach science and mathematics with technology: Developing a technology pedagogical content knowledge. Teaching and Teacher Education, 21, 509-523. https://doi.org/10.1016/j.tate.2005.03.006

Niess, M. L. (2008). Guiding preservice teachers in developing TPCK. In AACTE Committee on Innovation and Technology (Ed.), Handbook of Technological Pedagogical Content Knowledge (TPCK) for Educators (pp. 223-250). New York: Routledge for the American Association of Colleges for Teacher Education.

Özmen, H. (2004). Learning theories in science instruction and technology-enhanced constructivist learning. The Turkish Online Journal of Educational Technology, 3(1), 100-111.

Şenel, A., \& Gençoğlu, S. (2003). Technology education in a globalizing world. The Journal of the Industrial Arts Education Faculty of Gazi University, 11(12), 45-65.

Shen, J. (2010). Nurturing students' critical knowledge using technology-enhanced scaffolding strategies in science education. Journal of Science Education and Technology, 19(1), 1-12. https://doi.org/10.1007/s10956-009-9183-1

Smolin, L., \& Lawless, K. A. (2011). Evaluation across contexts: Evaluating the impact of technology integration professional development partnerships. Journal of Digital Learning in Teacher Education, 27(3), 92-98. https://doi.org/10.1080/21532974.2011.10784663

Stobaugh, R. R., \& Tassell, J. L. (2011). Analyzing the degree of technology use occurring in pre-service teacher education. Educational Assessment, Evaluation and Accountability, 23(2), 143-157. https://doi.org/10.1007/s11092-011-9118-2

Tarman, B., \& Baytak, A. (2011). The New Role of Technology in Education: Social Studies Teacher Candidates' Perceptions. Gaziantep University Journal of Social Sciences, 10(2), 891-908.

Taş, H. İ., Özel, A., \& Demirci, A. (2007). Geography teachers' perspectives on technology and the level of utilization of technology. Dumlupinar University Journal of Social Sciences, 19, 31-52.

Thurmond, V. A. (2001). The point of triangulation. Journal of Nursing Scholarship, 33(3), 253-258. https://doi.org/10.1111/j.1547-5069.2001.00253.x

Tor, H., \& Erden, O. (2004). A research about primary school students level who takes advantage from information technology. The Turkish Online Journal of Educational Technology, 3(1), 120-130.

Turkish Higher Educational Council. (2014). Turkish science teacher education. Retrieved April 24, 2014, from http://www.yok.gov.tr/documents/10279/49665/fen_bilgisi/f385bc78-22df-497d-bfca-7aee80c75c22

Yavuz, S., \& Coşkun, A. E. (2008). Attitudes and perceptions of elementary teaching through the use of technology in education. Hacettepe University Journal of Education, 34, 276-286.

Yıldırım, A., \& Şimşek, H. (2006). Qualitative research methods in social sciences. Ankara: Seçkin Publishing. 
Young, J. R., Young, J. L., \& Hamilton, C. (2013). The use of confidence intervals as a meta-analytic lens to summarize the effects of teacher education technology courses on preservice teacher TPACK. Journal of Research on Technology in Education, 46(2), 149-172. https://doi.org/10.1080/15391523.2013.10782617

\section{Copyrights}

Copyright for this article is retained by the author(s), with first publication rights granted to the journal.

This is an open-access article distributed under the terms and conditions of the Creative Commons Attribution license (http://creativecommons.org/licenses/by/4.0/). 